\title{
Development, Validation and Reliability of Schizophrenia Stage Inventory (SSI)
}

\section{Mohammad Aziz Shah Mohamed Arip, Khoo Jing Bei, Yong Mei Yeh}

To Link this Article: http://dx.doi.org/10.6007/IJARBSS/v11-i11/11043～DOI:10.6007/IJARBSS/v11-i11/11043

Received: 04 September 2021, Revised: 07 October 2021, Accepted: 29 October 2021

Published Online: 14 November 2021

In-Text Citation: (Arip et al., 2021)

To Cite this Article: Arip, M. A. S. M., Bei, K. J., \& Yeh, Y. M. (2021). Development, Validation and Reliability of Schizophrenia Stage Inventory (SSI). International Journal of Academic Research in Business and Social Sciences, 11(11), 1542-1553.

\section{Copyright: @ 2021 The Author(s)}

Published by Human Resource Management Academic Research Society (www.hrmars.com)

This article is published under the Creative Commons Attribution (CC BY 4.0) license. Anyone may reproduce, distribute, translate and create derivative works of this article (for both commercial and non0-commercial purposes), subject to full attribution to the original publication and authors. The full terms of this license may be seen at: http://creativecommons.org/licences/by/4.0/legalcode

Vol. 11, No. 11, 2021, Pg. $1542-1553$

Full Terms \& Conditions of access and use can be found at http://hrmars.com/index.php/pages/detail/publication-ethics 


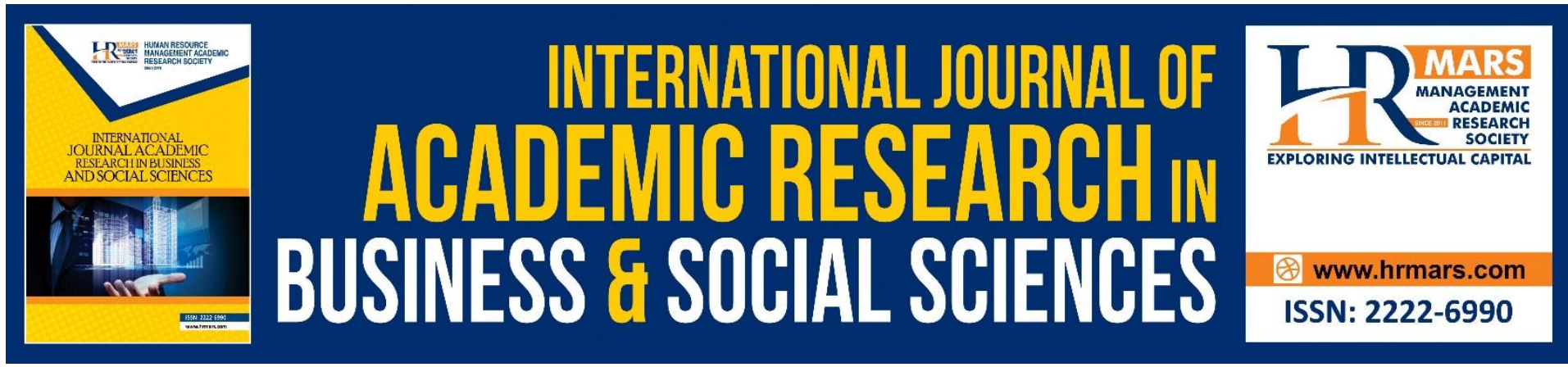

\title{
Development, Validation and Reliability of Schizophrenia Stage Inventory (SSI)
}

\author{
Mohammad Aziz Shah Mohamed Arip \\ Professor, Faculty of Human Development, Sultan Idris Education University, 35900 \\ Tanjong Malim, Perak, Malaysia \\ Email: aziz.shah@fpm.upsi.edu.my
}

Khoo Jing Bei, Yong Mei Yeh

Faculty of Human Development, Sultan Idris Education University, 35900 Tanjong Malim,

Perak, Malaysia

Email: edcounseling.psy@gmail.com, edcounseling.psy@gmail.com

\begin{abstract}
This study aimed to develop, validate the content and reliability of the Schizophrenia Stage Inventory (SSI). SSI is built based on the integration of the symptoms of Schizophrenia which have been described by the Ministry of Health Malaysia as mental disorders, perceptual disorders and behavioral disorders. Overall, SSI has 21 items divided into Sub Scale 1: Disturbing Thinking (7 items), Sub Scale 2: Perceptual Disorder (7 items), and Sub Scale 3: Behavior Disruption (7 items). The SSI was given to twelve expert's panel which consists of six member of the academics and six lecturers of Guidance and Counseling Courses. The SSI has good content validity for overall of 8.76 , while the validity of the content based on the Mindset Disorders sub-scale is 8.80 , the Perception Disorders sub-scale is 8.70 , and the Behavioral Disorders sub-scale is 8.80 . This indicates that SSI has high content of validity. The reliability of SSI was tested randomly among 45 respondents consisting of social workers. The overall reliability analysis of the SSI was as high as .950, while for sub-scale analysis it showed good results for Mindset Disorders, Perception Disorders, and Behavioral Disorders subscale. Thus, the reliability and validity of SSI findings were good and could be helpful for institutions of higher learning, workplaces and schools in terms of to identify the level of schizophrenia in an individual.
\end{abstract}

Keyword: Schizophrenia Stage Inventory, Content Validity, Reliability, Schizophrenia, Counseling

\section{Introduction}

Esther, Gill and Hanim (2005) from University Malaya Medical Center (UMMC) report a research on the early detection of schizophrenia was defined as illness before a person reaches 18 years old. According to Mohanraj (2014) in the Star news, schizophrenia oftenly developed during teenage or adulthood and had affected nearly 26 million people in the whole world. For the past 10 years, Malaysia had made an extensive research on 
schizophrenia symptoms profile. McLean et al (2015) had published article about the symptoms of schizophrenia among the lban community in Sarawak. The result of the study shows there are different profiles found in the community, whereby they performed fewer disturbing thoughts but more on hallucination and irregular behaviors. The Iban community also shown a short period of prodrome schizophrenia, they were more on the material usages and older age to develop psychosis symptoms instead of Australians and Indian community. With that, it was proven the number of people with schizophrenic disease is increasing until now. By understanding the seriousness of schizophrenia, our country had developed the National Mental Health Registry (NMHR) on 2003.

The NMHR was formed by the Ministry of Health (MoH) in order to collect the informations on people who has mental illnesses in Malaysia. Schizophrenia was the main type of mental illness focused by the NMHR. The registry collected informations on patients with schizophrenia in Malaysia was in order to assess the risk factor and interventions that could be made, whereby it also can ease the planning and evaluation of mental health service in the country. The NMHR contributions on schizophrenia disease was their first publication on 2008 in the Malaysia Medicine Journal. The result of the study reported that there were $7.7 \%$ up to $43.0 \%$ from every 100,000 citizen. The duration of untreated disease was at a median of 12 months and $20 \%$ of them experienced at least 2 comorbid diseases. Based on Hang et al (2002) from UMMC study mentioned that $54 \%$ of the schizophrenic patients in Permai Hospital (one of the largest mental health institutions in Malaysia) had a moderate to low understanding of this disease. The least understanding of the disease has affected their daily life due to not taking the right type medication and therapy.

In conclusion, without the right prevention that suits with the cultural background of this county on schizophrenia risks like the Malay version of schizoprenia stages inventory, it will bring to an increasing cases of schizophrenia disease in Malaysia. With that, this research aimed to develop an inventory that is valid and reliable called the Stages of Schizophrenia Inventory (SSI) in order to help all of the agencies and service institutions that was involved can use this inventory as an early detection in order to avoid an increasing number of schizophrenia cases.

\section{Background of Study}

Schizophrenia Stage Inventory (SSI) was developed to assess the schizophrenic stages on an individual. This inventory was characterized as uni-dimensions because it was build based on the schizophrenia disease symptoms consist of the patients' thoughts, perceptions and also behaviors. The origin name of "Schizophrenia" was from Greek, the word "schizo" was defined as divide or break and "phrenia" means thoughts. Schizophrenia is a disease that consisted in the brain and causes an irregular and disturbing thoughts, perceptions, emotions and behaviors (Nuraenah, 2012). Based on Abd Kadir (2012), schizophrenia was defined as a brain disorder similar to seizure, senile and multiple sclerosis. This disease usually started to develop among those who will be reaching their adulthood. He also mentioned that there are 3 signs of schizophrenic disease, it consists of thoughts disturbance (delusions), perception disturbance (hallucinations) and irregular behaviors.

Maramis (1990) states that delusional disturbance was a belief on thoughts that were not suitable with a person's reality, intellectual and cultural background. Those thoughts disturbance and false beliefs were defended eventhough there were proves of its' confusions 
and it was not parallel with their educational background and social culture of the concerned people. Delusions was a strong false belief that can't be sued with a sane opinion. According to Kiran and Chaudhury (2009), delusion is a false belief and can affect on a person's thoughts and it was not related to their background, religion or intelligence level. Based on John (2019), delusion is a theory or a truly false belief even there were proves that shows it is false. Delusions was divided into a few types, which were paranoid delusion, controlled delusion, awkward delusion, grandiose delusion, nihilistic delusion and reffered delusion.

Based on Tajudin and Tajuid (2016), hallucination occurred when a person experienced seeing, hearing and feeling something that was not existed. It has affected due to their health or thought disturbance and maybe an after-effect on drugs abuse. In addition, Teeple, Caplan and Stern (2009) mentioned that hallucination is an individual perception towards an object or an event (with all senses) without involving the outer stimulant from the patient's experience including the terms and conditions provided based on the psychiatrist, neurologist and oftalmologist. Based on John (2019), hallucination is a sense or perceptions faced by a person without involving any relevant outer stimulant. Hallucination was divided into hearing hallucination, sight hallucination, somatic hallucination, smell hallucination and taste hallucination.

Irregular behavior was defined as a strange and inconsistent temperament. Shizophrenic patients faced a burden to arrange their thoughts. They may unable to keep on track with the topic that was discussed in a group and the people around them will think that they were rude or wanted to not continuing the discussion. Moreover, when they talked, their sentences do not give any meaning. They were uncapable to do their daily activities well and always avoid interacting with the community. In conclusion, irregular behavior is an uncontrolled behavior.

\section{Literature Review}

According to the National Mental Health Registry (NMHR) and Mental Health Report from 2003 to 2005, there were 7351 schizophrenic patients who were hospitalized (Ministry of Health Malaysia, 2006). The number of patients were increasing with 2,000 new cases reported yearly. Life as a schizophrenic patient is a burden because they need to take their medications regularly and seek for treatments to prevent the illness getting more serious in the future. Unfortunately, most of the patients with schizophrenia do not seek treatment or not complied towards their medications and may end up with a relapse (Nor et al., 2020). Patients tend to act aggressive, emotional, paranoid and hostile towards other people. This condition is characterized by severe mental disorders, and some parties have been harassing their families with these mental disorders (Eric, 2011). The society still considers schizophrenia to be a "disease" caused by demons or curses, rather then mental illness. Thus, results in seeking for medical efforts being rejected by the family.

Schizophrenia is actually a chronic disease and illness. Individuals with schizophrenia experienced cognitive disorders, perception disorders and behavioral disorders such as hearing voices that others do not hear and believe that people are reading their minds (Hawyer et al., 2008). According to the DSM IV-R (from the Journal of Psychiatry, 2008), schizophrenia is a disorder that occurred atleast for six months with an active symptom such as delusions, hallucinations, disorganization in speech, abusive behaviors and negative symptoms for a month. The characteristics of those who were severely ill, they will have an emotional disturbance, get themselves lost from the reality and showing inappropriate 
behavior. Lindenmayer and Khan (2006) also found that about $50 \%$ to $70 \%$ of patients with schizophrenia suffers from hallucinations, delusions or both.

Delusions is one of the symptoms in Schizophrenia disease. It was defined as a false belief but it is truly believed, also called as a confusion of thought content. Delusions are named as the bases of madness (Jaspers, 1963). Based on McKay and Cipolotti (2007), as a schizophrenic patient, there are two theories on delusions which namely delusions of motivation and delusion of deficits. Delusions of motivation views more optimistic as they consider these beliefs as a way to reduce and overcome stress and anxiety. In contrast, the delusion of deficit believe that it existed due to brain dysfunction and caused cognitive or perception disorders.

Hallucinations is a perception disorder that had occurred in the life of patients diagnosed with schizophrenia. They can feel, hear, see and smell something that does not existed. A study by McGuire, Muray and Shah (1993), their study had a suprising finding when they found out the patients who were hallucinates, the most active part of the brain is the Broca area. This section of the brain involves in producing speeches. Since the auditory hallucination usually involves understanding on other's speech, the expected frequent part of the activity would be the Wernicke section which is on the involvement of language comprehension. This study has supported the findings of previos studies by Cleghorn et al. (1992) who found the Broca area is more active than Wernicke area among schizophrenia patients with hallucinations. Moreover, these observations also support the theory of metacognition in which hallucinated individuals do not hear the people's voices but they hear their own thoughts or voices and unable to distinguish them (Potkin \& Ford, 2009).

Further studies of behavioral disorders are less informative compared to delusions and hallucinations. Behavioral disorders are also symptoms of irregularities. It includes a variety of irregular behaviors that affect speech ability, motor behavior, and emotional reactions. The circulation of this behavior is unclear. According to Durand and Barlow (2013), irregular symptoms have two namely irregular speech and the second is inappropriate and irregular behavior. Conversations with schizophrenia patients are usually very frustrating because they can't understand the actual content of the conversation and makes it very difficult. These patients are usually less intelligent and aware of the problems they face. In fact, they experience associative splitting as termed by Bleuler (1908) referring to speech problems including shifting one issue to another and sometimes talking nonsense. Patients who show symptoms of inappropriate behavior are like laughing or crying at inappropriate times and situations. Sometimes they show strange behavior such as displaying behavior or behaving strangely in public. Patients with schizophrenia are also very active in showing behavior that is not same as the norm of society and out of the ordinary. Occasionally, patients also show catatonia involving motor dysfunction.

Based on the literature review conducted by previous researchers, it can be concluded that the study explains the seriousness of schizophrenia disease. Moreover, the literature review can be used as a guide by researchers in conducting studies related to the validity and reliability of schizophrenia level inventory. 


\section{Theoretical Principle on Schizophrenia Stage Inventory Development}

Schizophrenia Stage Inventory (SSI) was build based on the early symptoms of schizophrenia disease on a person. Schizophrenia also could be noticed through three signs which were delusions, hallucinations and behavioral disorder. The three signs were used as the main elements to build this inventory. Eventhough these elements can be measure separately, but mainly, they were related to each other. As for the Schizophrenia Stage Inventory, it was divided into three statements which were delusional statement, hallucination statement and behavioral disorder statement in order to prove a person was diagnosed with schizophrenia. As an example, based on the item in delusional statement number 1: I believe there are people who wanted to hurt me, hallucination statement number 1: I always heard someone whispering beside me, behavioral disorder number 1: Suddenly I laughed loudly. If those three items were ticked as YES, it shows that the person may have symptoms of schizophrenia disease.

\section{a) Delusional Statement}

Delusion is a strong false belief that can't be distorted by a wise thinking. Based on Kiran and Chaudhury (2009), delusion is a false belief and it can affect a person's thoughts. It is a false belief that was not occurred due to their religion background or intelligence.

\section{b) Hallucination Statement}

Based on John (2019), halluncination is a sensation or a sense of perception that a person has without any outer relevant stimulus effected. Hallucination was divided into hearing hallucination, sight hallucination, somatic hallucination, taste hallucination and scent hallucination.

\section{c) Behavioral Disorders Statement}

Behavioral disorder was defined as a strange behaviour that changes frequently. A schizophrenic patient tends to have a hard time to arrange their thoughts accordingly. They maybe unable to keep on with a topic that were discussed with a group of people. When they spoke, they can't provide any meaningful sentences. Behavioral disorder is uncontrollable and may affect their self-care and relationship with others.

Overall, the community should be cautious and get informations about schizophrenia disease to understand about schizophrenic patients. The most worrying thing that may happen if the patient's condition is severe and did not get any treatment immediately.

\section{Purpose of Study}

The purpose of the study was:

a. To develop the Schizophrenia Stage Inventory (SSI) based on literature review.

b. To obtain the validity value of SSI inventory through professional's evaluations.

c. To obtain the validity value of SSI subscales through professional's evaluations.

d. To obtain the reliability value of SSI inventory through the Cronbach Alpha analysis.

e. To obtain the reliability value of each of SSI inventory subscales through the Cronbach Alpha analysis. 


\section{Administration, Scoring and Interpretation of Schizophrenia Stage Inventory}

Schizophrenia Stage Inventory (SSI) is an inventory that measures the signs of a person with schizophrenia disease. SSI contained 21 items with 3 sub scales and each sub scales contained 7 items. The SSI will only tooks 10 to 15 minutes of administration. A condusive and comfortable situation would be an ideal situation to answer the inventory. Before the inventory was administrated, explanation on the terms and conditions need to be clear towards the respondent. The respondent needs to answer honestly based on the statement that describe themselves. The 'Yes' or 'No' answer need to be circled on the answer sheet.

The respondents were free to answer the statements based on their own view and relations with themselves. The respondens were told not to be worried about their answers because there will no right and wrong answers. The SSI answer form were based on dichotomy scale, either it is a Yes or No. Based on the scoring, 'Yes' is consider as 1 and 'No' is 0 . As for analysis and score interpretation, SSI was divided into three levels which are low level, medium level and high level. The low level was denoted with a score of 0 to 7 , while medium level scores 8 to 16 and high level scores is 17 to 24 . These scores will indicate the schizophrenic level in patients. Those patients who have a low and high score were adviced to get further treatment with a psychiatric as soon as possible.

\section{Research Method}

A descriptive study with a purpose to get the reliability and validity value of the SSI. This study consists of 3 phases, which are Phase 1: Development of SSI, Phase 2: Reliability Analaysis of SSI and Phase 3: Validity Analysis of SSI

\section{Phase 1: Development of SSI}

SSI was developed based on the early simptoms of schizophrenia disease. It can be observed through three main signs which are delusions, hallucination and behavior disorder. With that, these three signs also indicate as the main elements in the development of this inventory. The inventory was also divided into three statement which are delusion statement, hallucination statement and behavioral disorder statement that will determine the stages of schizophrenic disease of the patient.

\section{Phase 2: Reliability Analysis}

Once the item was successfully developed, SSI was submitted to 12 professional panels for a review on the reliability of the inventory. The panels consist of five academicians from higher instituions and seven school counselors. The reliability of a study is very important as a true statement and explanation on the characteristics of the inventory (Hammersley, 1995).

\section{Phase 3: Validity Analysis}

The purpose of phase three was to get the inventory value of validity. The validity value was usually referred to show the stability and inner consistency (Creswell, 2005). A great validity value of an inventory as mentioned by Kerlinger (1979), the inventory that have the $\alpha$ (alpha) value more than 0.6 with a significant value of 0.05 . When the reliability and validity value of SSI was taken, it had administered to 45 people. The sample design is random sampling. The result of the study will be analysed by SPSS in order to get the Cronbach Alpha value to get the validity value of SSI. 


\section{Subjects of Study}

The subjects of the study only involved in second and third phase. In the second of the study, 12 professional panels consist of academiciana in higher institutes, psychologist and school counselors. Meanwhile in phase three, 45 people was choosen to get the SSI validity and reliability value.

\section{Results of Study}

\section{Result Phase 1: Scale Development, Sub scales and SSI items}

SSI was developed based on the literature review from variety sources such as books, articles and journals about the early symptoms on schizophrenia disease on a person. By referring to the DSM IV-R, schizophrenia is a disturbance that occurred atleast six months including the active phase for a month followed with delusions, hallucinations, speech disorganization, aggressive behaviors and negative symptoms. For the development of Schizophrenia Stages Inventory, it consists of 21 items and the items were divided into three subscales which are, subscale 1: Delusions ( 7 items), subscale 2: Hallucinations ( 7 items) and subscale 3: Behavioral disorder (7 items).

\section{Result Phase 2: SSI value of Validity}

Based on the agreement from the professional panels, the SSI validity value was explained in Table 1.

Table 1: Validity value of Total SSI and SSI subscales ( $n=12)$

\begin{tabular}{lccc}
\hline \multicolumn{1}{c}{ Scales/ Subscales } & Number of Items & Percentage (\%) & Result from Experts \\
\hline Total SSI & 21 & $8.74(87.4 \%)$ & Acceptable \\
Delusions & 7 & $8.58(85.8 \%)$ & Acceptable \\
Hallucinations & 7 & $8.93(89.3 \%)$ & Acceptable \\
Behavior Disorders & 7 & $8.70(87.0 \%)$ & Acceptable \\
\hline
\end{tabular}

Based on Table 1, it shows that the validity total SSI is 8.74 (87.4\%). Meanwhile the validity valur for each subscale was; Delusions 8.58, Hallucinations 8.93, Behavior disorders 8.70. The result shows that SSI have a high value of validity.

Result Phase 3: SSI value of Reliability

SSI reliability analysis was explained in Table 2.

Table 2: Reliability of SSI items and sub scales ( $n=45)$

\begin{tabular}{lccc}
\hline Test Reliability & Number of Items & Cronbach Alpha & Result \\
\hline Total SSI & 21 & .703 & Moderate \\
Delusions & 7 & .307 & Low \\
Hallucinations & 7 & .553 & Moderate \\
Behavior Disorders & 7 & .575 & Moderate \\
\hline
\end{tabular}

Based on Table 2, the SSI reliability analysis shows a moderate and satisfied value of Cronbach Alpha coefficient, 0.703 . Based on Kerlinger (1979), the main reliability value of a questionnaire with $\alpha$ (alpha) value more than 0.6 significant level of .05 , indicates a great reliability value. With that, the result had clearly show that SSI has a high inner reliability value and it can measure the early schizophrenia symptoms. As for the SSI subscale reliability has a low reliability value, which were Delusion .307, meanwhile as for Hallucination has a moderate value of .553 and Behavioral Disorder .575. The SSI value is moderate. Based on 
Sekaran (1992) mentioned that reliability value less than 0.6 were considered low and can't be acceptable, meanwhile the value between 0.6 to 0.8 is considered moderate and acceptable and 0.8 and above, the value considered great and highly acceptable.

Next, based on Table 3, it shows the reliability for each item in SSI. The item 1, 4, 7, 10, 13, 16 and 19 it is for Delusions subscale. Meanwhile item 2, 5, 8, 11, 14, 17 and 20 is for the Hallucination subscale. Moreover, the item 3, 6, 9, 12, 15, 18 and 21 is for the behavioral disorder subscale. The reliability value was present as below:

Table 3: Reliability of SSI Items

\begin{tabular}{clc}
\hline Bil & \multicolumn{1}{c}{ Item } & Alpha Cronbach \\
\hline 1 & I believe that other people would abuse me. & .752 \\
2 & I always heard people talking near me. & .693 \\
3 & I suddenly laughed loudly. & .668 \\
4 & I felt like there is a creature inside my body. & .696 \\
5 & I felt some unsual movement inside my body. & .680 \\
6 & I shaked hands with people unconsciously. & .680 \\
7 & I believe that I can communicate with the Supernaturals. & .691 \\
8 & I always scent something different. & .677 \\
9 & I always copy how other people walks. & .687 \\
10 & There is someone who wanted to bring me down. & .706 \\
11 & I saw people arguing but, in the reality, they were just talking & .702 \\
12 & I waved my hands without any directions. & .681 \\
13 & I believe that the earth is splitting. & .706 \\
14 & I have seen dead people come to me. & .702 \\
15 & I am able to keep a posture within a long period of time. & .699 \\
16 & I always pressed to do aggressive behaviors. & .707 \\
17 & I always heard things that other people can't hear. & .674 \\
18 & I always repeat the same sentences. & .677 \\
19 & I believe that my heart beat stopped. & 0 \\
20 & I felt someone always pat on my body. & .680 \\
21 & I talked without anyone understands it. & .699
\end{tabular}

Based on the Table 3 above, the least reliability value is 0 for the item number 19, meanwhile the highest Cronbach Alpha value is 0.752 on the item number 1 under the Delusions subscale. This analysis shows that the reliability value for each of SSI items were moderate. It is also indicating that the quality of the items build was at the moderate level, satisfied and understandable for the responden. Moreover, the reliability value was supported with the statement by Mohd Majid Konting (1998), an acceptable reliability value is 0.60 and above.

\section{Discussion and Suggestion}

This study can give a large implication for psychologist and counsellors in Malaysia. The development of SSI was based on the literature reviews on the definition, concept, factors and symptoms of schizophrenia disease. Next, the theory as mentioned by the National Health Ministry, have been the main framework to develop the SSI subscales. This main theory has been the guidance in order to develop the items of the inventory. With that, SSI was built with 21 items under three subscales that measures the stages of Schizophrenia disease which are Delusions, Hallucinations and Behavioral Disorder. 
From the analysis of study, SSI shows a high value of validity and a moderate reliability value. Based on Kerlinger (1979), the reliability value of a questionnaire with a $0.6 \alpha$ (alpha) significant to 0.5 as a great value. A high validity value shows the professional panel were in the same page where the SSI items were able to measure the definition scales and every sub scale in SSI. Sekaran (1992) mentioned if the reliability value is less than 0.6, the value is considered low and unacceptable. Meanwhile, if the value is 0.6 to 0.8 , it is at a moderate value and acceptable, and for the value 0.8 and above, it is considered great and acceptable. The result of the study had proved that SSI can measure the schizophrenia stages with three sub scales whice are Delusions, Hallucinations and Behavioral Disorder.

Based on the result, the researchers had suggested that SSI can be applied in all high educational institutions and work places to look on the level of schizophrenia in each individual in order to build a healthy and positive future generation. Next, a further research should be done to get a better statistical analysis towards the SSI items as example, replacing the item number 19 with other items. This is important to improvise the sub scales and items build to a better standard and quality. The research respondents also should be varied and expanded to different groups of people and ages to produce a quality SSI version in the future. Besided that, implementing a relationship between the schizophrenia stages and variables such as gender, environment factors, parents teaching and other factors that can influence a person.

A few considerations and suggestions were recommended to those who wanted to apply the same research in the future. One of it was personal research and use different places such as government and private agency and the research can be use for data collection. Besides that, a further research needs to use more than one places, agency or university to look on a higher value of reliability and validity. All of the suggestions were also considered as a requirement to improve a research and an inventory to get a good and high quality result in the future (Abrams, Ando \& Hinkle, 1998).

\section{Conclusion}

Overall, this research was had successfully build an inventory called Schizophrenia Stages Inventory (SSI). The inventory consisted a high reliability and a moderate validity value. With that, SSI can measure the schizophrenia stages with three sub scales which were Delusions, Hallucinations and Behavioral Disorder. The analysis in each of the items were found that the quality of the items was moderate, acceptable and easy to understand by the respondents. In conclusion, this research had shown that SSI have a moderate value of reliability and validity and it also can be used as an instrument to measure a person's stage of schizophrenia.

\section{References}

Abrams, D., Ando, K., \& Hinkle, S. (1998). Psychological attachment to the group: Crosscultural differences in organizational identification and subjective norms as predictors of workers' turnover intentions. Personality and Social psychology bulletin, 24(10), 1027-1039.

Bleuler, E. (1908). Die Prognose der Dementia praecox (Schizophrenie-Gruppe). Allg $Z f$ Psychiat Psychisch-Gerichitliche Medizin, 65, 436-464. 
Cleghorn, J. M., Franco, S., Szechtman, B., Kaplan, R. D., Szechtman, H., Brown, G. M., Nahmias, C., \& Garnett, E. S. (1992). Toward a brain map of auditory hallucinations. American Journal of Psychiatry, 149, 1062-1069.

Creswell, J. W. (2005). Educational research: Planning, conducting, and evaluating quantitative and qualitative research. Upper Saddle River, NJ: Pearson.

Andrew Mohanraj (2014). World Mental Health Day - Living with Schizophrenia. Retrieved on 25 October 2019 from https://www.thestar.com.my/authors?q=Datuk+Dr+ Andrew+Mohanraj.

Durand, V., \& Barlow, D. (2013). Essentials of Abnormal Psychology. 6th ed. Wadsworth: Cengage Learning.

Eric. (2011). About 20,000 People with Severe mental Disorder (Skizofrenia) in Indonesia Live in The Stocks. Retrieved on 15 October 2019 from http://autobacklinkdirectory.blogspot.com/2011/10/about-20000-peoplewithsevere-mental.html.

Esther, E., Gill, J. S., Hanim, A. H. (2005). Outcome study of early onset schizophrenia. Malaysian Journal of Psychiatry 2005; 13(1): 20-26.

Hammersley, M. (1995). The Politics of Social Research. California: Sage Publications.

Hang, T. J., Ming, B. C. T., \& Ahmad Hatim Sulaiman (2002, August). Assessment of insight in patients with schizophrenia in Hospital Permai. In Proceedings of the 4th Johore Mental Health Convention (pp. 23-24).

Hawyer, F., Mackinnon A., Farhall J., Sims E., Blaney S., Yardley P., Daly M., Mullen P. \& Colopov, D. (2008). Acting on harmful command hallucinations in psychotic disorders. The Journal of Nervous and Mental Disease, 196(5), 390-398.

Jaspers, K. (1963). Generai Psychopathology (7th edn) (trans. J. Hoenig \& M. W. Hamilton). Manchester: Manchester University Press.

John, M. G. (2019). Schizophrenia Basics: Delusions, Hallucinations \& Onset. Retrieved on 15 October 2019 from htts://psychcentral.com/lib/schizophrenia-basics-delusionshallucinations-onset/

Kerlinger, F. N. (1979). Behavioral research: A conceptual approach. NewYork: Holt, Rinehart, and Winston.

Kiran, C., \& Chaudhury, S. (2009). Understanding delusions. Industrial Psychiatry Journal, Vol. 18 issue 1

Lindenmayer, J. P., \& Khan, A. (2006). Psychological disorder. In J. A. Lieberman, T. S. Stroup, \& D. O. Perkins (Eds.), Textbook of schizophrenia. Washington, DC: American Psychiatric Publishing.

Maramis. (1990). Catatan Ilmu Kedokteran Jiwa. Surabaya: Airlangga University Press.

McGuire, P. K., Murray, R. M., \& Shah, G. M. S. (1993). Increased blood flow in Broca's area during auditory hallucinations in schizophrenia. The Lancet, 342(8873), 703706.

McLean, D., Barrett, R., Loa, P., Thara, R., John, S., McGrath, J., McGrath, J., \& Mowry, B. (2015). Comparing schizophrenia symptoms in the I ban of $S$ arawak with other populations to elucidate clinical heterogeneity. Asia-Pacific Psychiatry, 7(1), 36-44.

McKay R., Cipolotti L. (2007). Attributional style in a case of Cotard delusion. Conscious. Cogn. 16: 349-59

Ministry of Health Malaysia (2006). National mental health registry schizophrenia report 2003 - 2005. Kuala Lumpur: National Mental Health Registry, NHMR (2006). 
Konting, M. M. (1998). Kaedah penyelidikan pendidikan. Kuala Lumpur: Dewan Bahasa dan Pustaka.

Nor, Z. M., Idris, I. B., Daud, F., \& Abd Rani, N. (2020). The Psychological Well-being of Patients with Schizophrenia on Follow Up Clinics in Three Psychiatric Hospitals in Malaysia.

Nuraenah (2012). Hubungan Dukungan Keluaarga Dan Beban Keluarga Dalam Merawat Anggota Keluarga Dengan Perilaku Kekerasan Di Rumah Sakit Jiwa Islam Klender Jakarta Timur. FIK UI.

Potkin, S. G., \& Ford, J. M. (2009). Widespread cortical dysfunction in schizophrenia: the FBIRN imaging consortium. Schizophrenia bulletin. California: department of Psychiatry and Human Behavior, University of California, 35(1), 15-18.

Sekaran, U. (1992). Research methods for business: A skill-building approach. New York: Wiley. 